\title{
User Experience Testing in the Open Textbook Adaptation Workflow
}

\author{
A Case Study \\ Camille Thomas, Kimberly Vardeman, and Jingjing Wu
}

\begin{abstract}
As library publishers and open education programs grow, it is imperative that we integrate practices in our workflows that prioritize and include end users. Although there is information available on best practices for user testing and accessibility compliance, more can be done to give insight into the library publishing context. This study examines the user and accessibility testing workflow during the modification of an existing open textbook using Pressbooks at Texas Tech University.
\end{abstract}

\section{INTRODUCTION}

As library publishers and open education programs grow, there is an opportunity to integrate into our workflows practices that prioritize and include end users. Although there is information available on best practices for user testing and accessibility compliance, more can be done to give insight into the library publishing context. There are currently no case studies that examine the user and accessibility testing workflow during the modification of an existing open textbook. This study examines user experience testing as a method to improve OER interfaces, learning experience, and accessibility during the OER production process using Pressbooks at a large research university.

\section{LITERATURE REVIEW}

User experience (UX) is a "momentary, primarily evaluative feeling (good-bad) while interacting with a product or service" that can go beyond simple usability evaluations to consider "qualities such as meaning, affect and value." ${ }^{1}$ UX evaluations are generally applied to library websites, spaces, and interfaces and are not currently a common element in library publishing workflows. Open Educational Resources (OER) are defined as teaching, learning, and research resources that reside under an intellectual property license that permits their free use and repurposing by others. ${ }^{2}$ Whitfield and Robinson make a distinction between teaching vs. learning resources, instructional vs. interface usability, and ease of modification for creators. ${ }^{3}$ This select literature review considers usability testing of e-books, OER workflows, and accessibility evaluations and how they apply to local contexts.

Along with incentives for instructors to engage with OER, the ability to adapt OER is often highlighted as a benefit. Walz shares common workflows for OER production, including broad steps for design and development during creation of original OER. ${ }^{4}$ In the case of reuse, the design stage in Walz's workflow includes review, redesign, redevelopment, and adoption. Open University models for transforming OER include the integrity model, in which the new OER remains close to the original material; the essence model, in which material is transformed by

Camille Thomas (thomas5@fsu.edu) is Scholarly Communications Librarian, Florida State University. Kimberly Vardeman (kimberly.vardeman@ttu.edu) is User Experience Librarian, Texas Tech University. Jingjing Wu (jingjing.wu@ttu.edu) is Web Librarian, Texas Tech University. (C) 2021. 
reducing some features and adding new activities for interactivity; and the remix model, in which content is redesigned to be optimal for web viewing. ${ }^{5}$ Student participation in OER production is often seen in open pedagogy, but these cases look at student frustrations and feedback with the objective of experiential learning, not for usability or evaluation. ${ }^{6}$ Now that OER production has grown in scale, librarians and advocates seek the most effective and sustainable workflows.

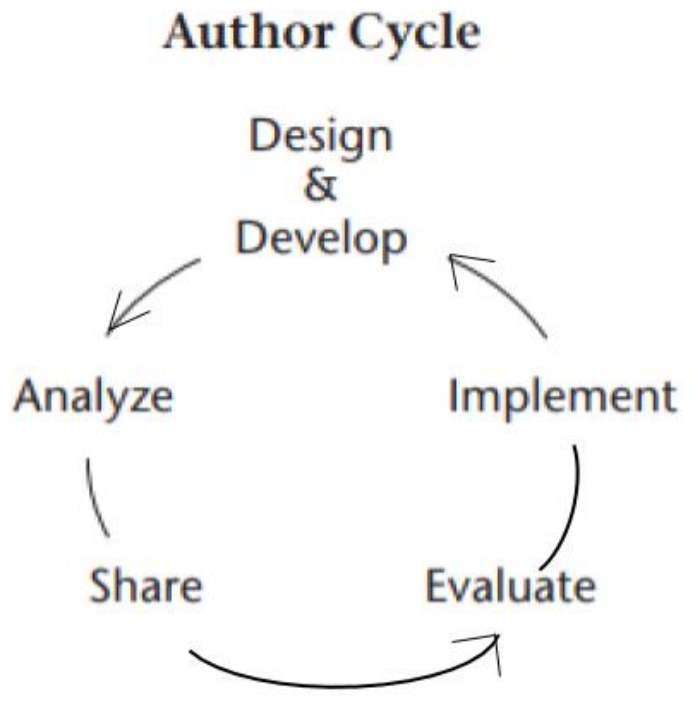

User/Re-Purposer Cycle

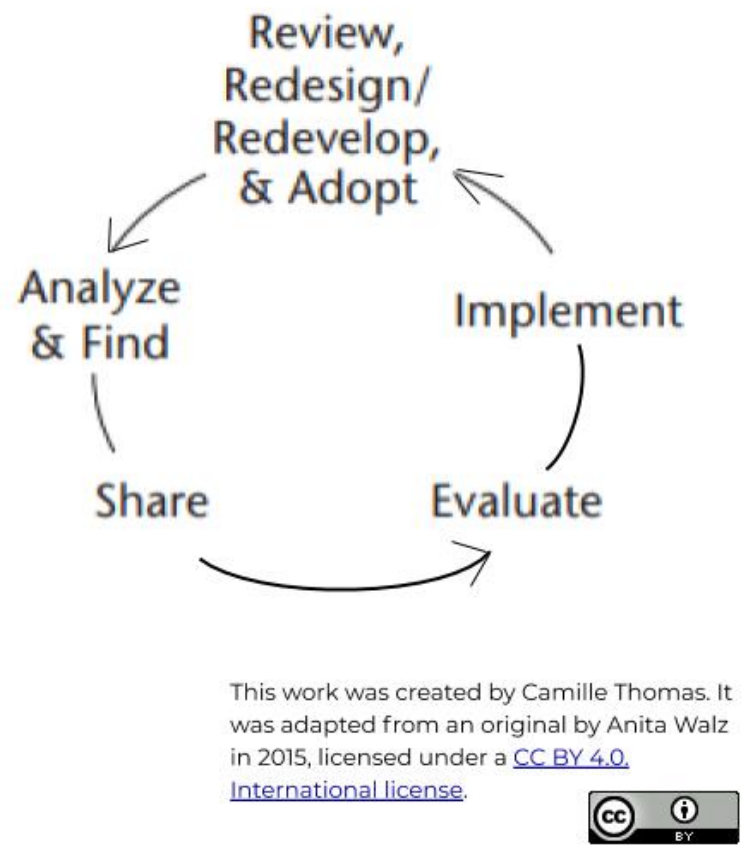

Figure 1. Illustrations of two OER lifecycles. This work was adapted by Camille Thomas from an original by Anita Walz (2015) under a CC BY 4.0 international license. $^{7}$

In his workflow and framework analysis Meinke recommends the inclusion of more discrete steps and believes each institution's ideal workflow will be based on local context. ${ }^{8}$ Usability testing is a discrete workflow step that gives us human-centered insight about how users are affected by interfaces and how they value systems. ${ }^{9}$ Libraries favor collections-based assessment that measures how many end users are using digital items, without prioritizing who users are or how and why they use resources. ${ }^{10}$ Demonstrating and assessing value is essential for scholar buy-in and content recruitment, for example, which are central to all types of open resources.

In the case of educational materials, lack of engagement and breakdowns in learning can be attributed to barriers and marginalization of learners. ${ }^{11}$ Additionally, critiques of OER include assumptions that access to information equates to meaningful access to knowledge, but without context there is no guarantee that there will be meaningful transference or learning. ${ }^{12}$ Harley believes defining a target audience and considering reasons for use and nonuse of resources in specific educational contexts beyond measuring anecdotal demand (e.g., website page views or survey responses, which Harley does not see as indicators of value but rather of popularity) may address challenges to effectively measuring outcomes for content that is freely available on the web. ${ }^{13}$ Meaningful evaluation of learning resources requires deep understanding of contextualized 
educator and student needs, not just content knowledge. ${ }^{14}$ To address these barriers and assumptions, OpenStax, a leading OER publisher, has UX experts on staff, but this model is exceptional and rare at a university or library. Many universities and libraries publishing OER do not have full-time personnel dedicated to review. Some library user experience departments have hired content strategists for auditing, analyzing, defining, and designing website content, contentrelated projects, and overall content strategy. ${ }^{15}$ Currently, OER work is rarely included in the scope of library user experience departments. However, limited literature does show the use of UX research methods in library publishing contexts.

Libraries and support units with few resources can also perform user testing. ${ }^{16}$ User experience practitioners have established that a low number of test participants - three to five-are enough to identify a majority of usability issues. ${ }^{17}$ Borsci et al. suggest the important aspect is not securing a high-volume sample, but rather finding behavior diversity to make reliable evaluations. ${ }^{18}$ The number of users required to find diverse behavior can depend on what is being tested. Following this standard, the consistent inclusion of user evaluations in OER workflows will not necessarily require large amounts of funding, participants, resources, or time.

OER, in particular, are well suited to cumulative, early, frequent, and specific user testing. With their open copyright licensing and availability, OER are an example of the mutable digital content needed for collaboration, cumulative production, and support of networked communities. ${ }^{19}$ Several studies assert that complete information behavior analysis should be carried out before or during development, not after. ${ }^{20}$ Meinke concludes his workflow analysis by encouraging iterative release in OER production workflows, which aligns with lean and iterative "guerilla" approaches used in libraries to sustainably improve usability. ${ }^{21}$ Iteration is a process of development that involves cyclical inquiry or repetitive testing, providing multiple opportunities for people to revisit ideas or deliverables in order to improve an evolving design until the end goal is reached. ${ }^{22}$ In the context of design, it is a method of creating high-quality deliverables at a faster rate. ${ }^{23} \mathrm{~A}$ cyclical approach also reflects Walz's as well as Blakiston and Mayden's workflow visualizations. ${ }^{24}$

Walz asserts that incentives for instructors and the quality of the resources are key factors in advancing adoption, adaptation, and creation of OER. ${ }^{25}$ Harley uncovered disconnects between what faculty say they need in undergraduate education and what those who produce digital educational resources imagine is an ideal state. ${ }^{26}$ Influence on faculty resource use, including OER, varied by discipline, teaching style and philosophy, and digital literacy levels, with personal preferences having the most influence on decision-making. In the evaluation or tracking stage found in most OER production workflows, we can see the impact of the quality assurance stage. The study by Woodward et al. on student voice in evaluating textbooks found that incorporating multiple stakeholders into the process resulted in deeper exploration of students' expectations when learning. Students ranked one OER and one conventional textbook the highest based on content, design, pedagogy, and cost. Multiauthored options ranked higher, and texts with examples were seen as more beneficial for distance learners. ${ }^{27}$

Meinke believes unless discrete parts of the development process are identified, it is not useful to signal others to contribute to a project. ${ }^{28}$ An example of an OER production workflow containing usability considerations is the Content, Openness, Reuse \& Repurpose, and Evidence (CORRE) framework by the University of Leicester (see fig. 2) ${ }^{29}$ The openness phase of the CORRE 2.0 framework includes "transformation for usability," which is assigned to the OER evaluator, editorial board, or head of department. ${ }^{30}$ Versions of the CORRE workflow were adapted by the 
University of Bath and the University of Derby in the United Kingdom for their institutional contexts. For example, the University of Derby assigned "transformation for usability" to a developer. By building usability as a discrete step in OER production workflows, publishers and collaborators can make improvements on pain points, make changes in context, and create clear guidelines for partnerships based on local needs. Betz and Hall's study supports considerations for how user microinteractions, or individual actions within a process, can be improved to make them scalable and commonplace in library workflows. ${ }^{31}$ This can include publishing workflows. For example, a study of OER on mobile devices in Brazil found problems related to performance, text legibility, and trigger actions in small objects. ${ }^{32}$ Other guidelines for OER and usability include using high-quality multimedia source material, advanced support from educational technologists, and balancing high and low technology in order to avoid assumptions about learners' internet connection or devices. ${ }^{33}$ Although usability testing alone is an important part of evaluating a website or product, because the user experience is multifaceted, it is also important to ensure that the product is accessible, meets user needs, and has an appealing design. ${ }^{34}$

\section{OSTRICH open Educational Resources}

\section{CORRE roles and responsibilities at Leicester}

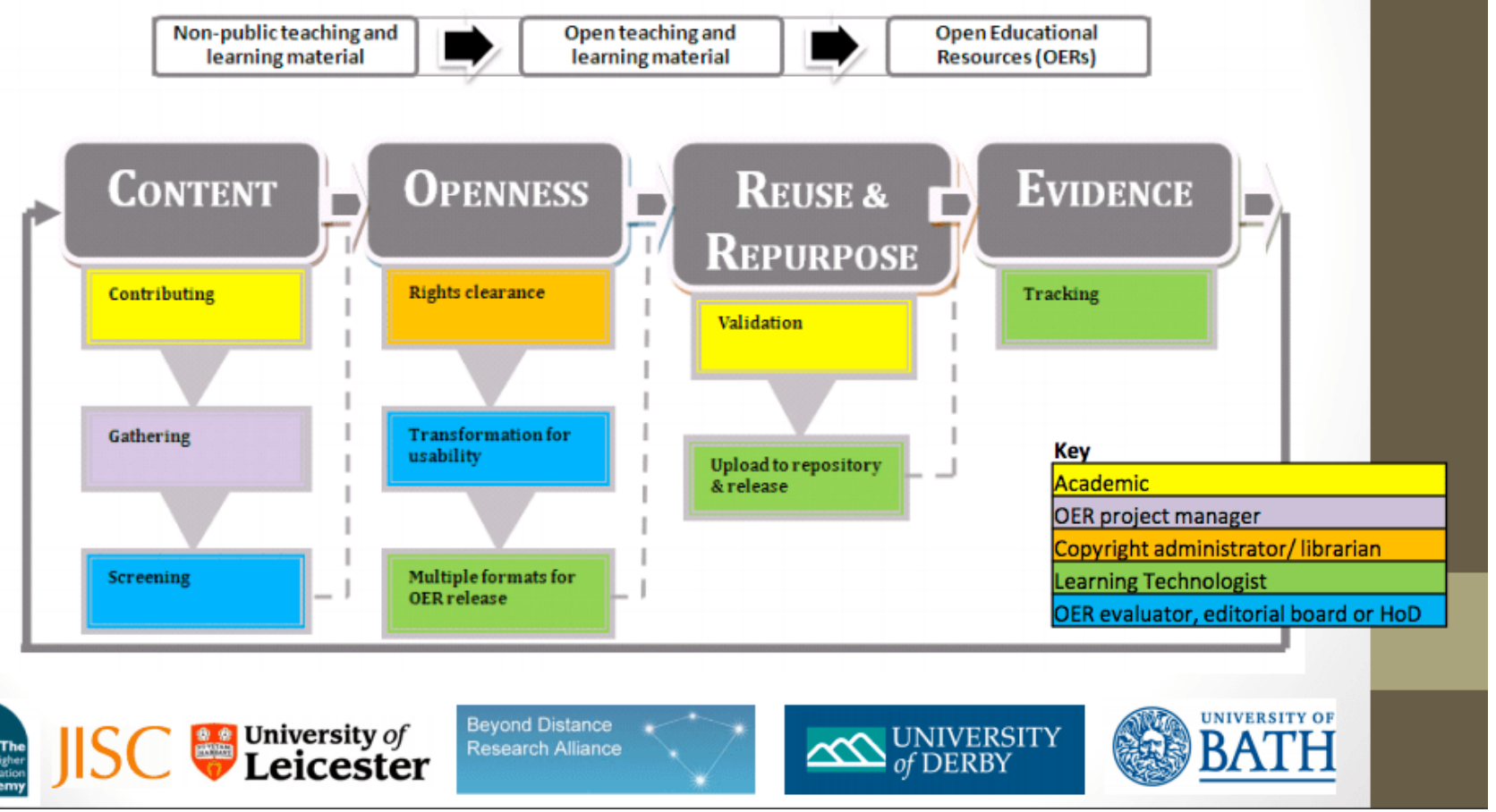

Figure 2. CORRE framework for OER development at the University of Leicester. ${ }^{35}$

Accessibility studies also encourage integrating user interactions into the creation workflow. Accessibility impacts usability, findability, and holistic user experience. ${ }^{36}$ Creators and supporting advocates have relied on universal design, web standards, and ADA compliance when creating 
accessible digital content, emphasizing that accessible content for those with disabilities means more accessible content for all users. ${ }^{37}$ Areas addressed can include text style and formatting, linking, and alternative text considerations, as detailed in the BCcampus Open Education Accessibility Toolkit. ${ }^{38}$ For example, Kourbetis and Boukouras drew from universal design to create a bilingual OER for students with hearing impairments in Greece, incorporating contextual considerations for vernacular languages and other local user needs. ${ }^{39}$

Early efforts toward accessible OER, such as a 2010 framework, prompted critiques from members of the accessibility community and impeded adoption. ${ }^{40}$ While guides based in universal design offer a starting place and consistent reference, OER advocates could create workflows that support adaptive changes seen in inclusive design. Universal design and web standards are fixed, while inclusive design seeks to support adaptive changes as needs evolve and does not treat nonnormative users as a homogenous, segregated group. ${ }^{41}$ Treviranus et al. go on to state that compliance is not achieved by providing a set of rules, guidelines, or regulations to be followed. ${ }^{42}$ Beyond lack of awareness of accessibility best practices, librarians and creators tend to have little control over customizing proprietary digital content platforms to add local context. ${ }^{43}$ The Flexible Learning for Open Education (FLOE) project, for example, aims to integrate automatic and unconscious inclusive OER design through open source tools, but many institutions may not be able to develop such tools to incorporate local contexts. ${ }^{44}$

Both librarians and e-resources vendors have been interested in the features and usability of ebooks to fine-tune their collection development strategies as well as improve the user experience of their platforms. Literature shows that most studies about e-books have focused on features or the interface design of e-book reading applications. The recent Academic Student Ebook Experience Survey showed that three-quarters of survey attendees considered it extremely important or important for e-books to have page numbers for citation purposes. ${ }^{45}$ This survey and other studies suggest that search, navigation, zoom, annotation, mobile compatibility, as well as offline availability including downloading, printing, and saving, were the most expected features. ${ }^{46}$ Other features, such as citation generation and emailing, were mentioned or tested in some research. ${ }^{47}$

While using e-books and using e-textbooks may involve the same functionality, the purpose, devices, and user types differ because knowledge transfer is needed in learning. Jardina and Chaparro evaluated eight e-textbook applications with four tasks: bookmarking, note-taking, note locating, and word searching. ${ }^{48}$ They found that the interfaces to these common features varied on the different applications. Standardization, or at least following general web convention when designing these interfaces, may reduce distractions that keep students from learning. The etextbook user interface can be critical to the future success of e-textbook adoption.

Although limited research on usability of e-textbooks or open textbooks has been conducted, a considerable number of findings from studies on e-books are relevant and applicable to etextbook projects. The e-book or e-textbook applications usability evaluation methods and results can be borrowed when understanding OER user needs. Libraries can apply these e-book usability evaluations to the basic infrastructure of OER, but leverage the local contexts of students, instructors, and institutional culture when adapting the material.

The more normalized usability, prototyping, and collaboration are in OER production workflows, the richer the resources and community investment. This approach can address diverse and evolving OER user needs, locally and sustainably, as they arise. Our study contributes to the 
literature by examining the impacts of integrating usability testing in an inaugural OER adaptation project at a large research university in the United States.

\section{CASE STUDY}

The project to adapt the open textbook College Success, published by the University of Minnesota Libraries, for use in the RaiderReady first-year seminar course, was brought to the Texas Tech University Libraries' Scholarly Publishing Office by the head of the outreach department in March 2018. The program was deciding between a commercial textbook and the adapted open textbook. The course was offered during each fall semester and had an average enrollment of over 1,600 since 2016. An initial meeting took place and regular weekly meetings were set up afterward to review edits and ensure communication within the original 30-day timeline. It was the first OER production project for the Libraries' publishing program, which had previously focused on open access journals and materials in the repository.

Originally, we sought to use Open Monograph Press because we had a local instance already installed. However, a platform with more robust formatting capabilities was needed in order to reach the desired product within the timeline. We decided to use the Pressbooks Pro (a WordPress plugin) sandbox for one project through our Open Textbook Network membership. A rough draft of edits to the original work were already completed. We used a mediated service model, in which librarians performed the formatting, quality assurance, and publishing. This was in contrast to self-service models in which creators work independently and consult with support specialists. The digital publishing librarian and scholarly communication librarian formatted the edits, with HTML/CSS customization and platform troubleshooting from the web librarian. Other library staff involved in the project included Communications \& Marketing (cover design), the user experience librarian, and the electronic resources librarian (cataloging in the catalog). Campus stakeholders and partners included the Libraries, the RaiderReady program, editors, CopyTech (printers affiliated with the university), the campus bookstore, and the Worldwide eLearning unit.

Program partners were enthusiastic about usability and accessibility testing for the textbook. The initial testing took place in the middle of the adaptation project timeline, once initial content was formatted and ready for testing. The BCcampus' Accessibility Toolkit and the Pressbooks User Guide were used as primary guides throughout the process. The scholarly publishing librarian and the user experience librarian met to develop the testing method and identify users who would reflect the audience using the textbook. A second round of tests was conducted a year after the initial project when the editors made updates to the text. While the resulting changes were minor, this further testing allowed us to seek more feedback on the most recent version of the textbook and apply some lessons learned from the first round of testing.

We did not use personas or identify user needs beforehand. We planned to recruit first-year students and students who took the RaiderReady course in a previous semester. However, we decided to instead recruit from existing pools of student volunteers for library usability tests in order to get three to six students in a short amount of time. For the second round of testing, we planned to recruit on-campus students, distance students, and students with diverse abilities. We recruited from newly established pools of volunteers for distance students as well as existing volunteer pools. During the first iteration, we requested that Worldwide eLearning, Texas Tech University's distance learning unit on campus, test the textbook pilot content in PDF and EPUB formats using screen reader software. 
The user experience librarian conducted a first round of four usability tests in March 2018 and a second round of two usability tests in April 2019. A sample test script from Steve Krug provided a solid foundation for conducting our own tests. ${ }^{49}$ In each test, participants were asked to answer two pretest questions, complete four tasks, and answer four posttest questions (see appendix for script). Tasks included finding the textbook, exploring the textbook itself, locating activities for a specific chapter, and searching for the student code of conduct. Participants were instructed to think aloud as they worked through the tasks. The think-aloud protocol is a commonly used test method, where participants are asked to verbalize their thoughts and actions as they perform tasks on a website. The observation tasks are set beforehand, and the facilitator follows a script to ensure consistency among testers. ${ }^{50}$ The combination of observing and recording participants' comments and reactions provides insight into a site's usability. Testers were invited to comment on their experience at the end of the session. Each usability test was recorded using Morae software to track on-screen activity such as mouse movements and clicks, typing, and the verbal comments of the facilitator and participant. We conducted tests using a laptop running Windows 10 with a 15.6-inch display. In the first round of testing, we also showed students the book on an iPad mini, both in Adobe Reader and iBooks. While we asked them to briefly view the textbooks, we did not ask them to complete specific tasks while using the tablet.

\section{LIMITATIONS}

The biggest limitation was that we did not test on users using a screen reader or other assistive technology. The user experience librarian built a pool of on-campus students who volunteered to participate in user research in 2018, and relationships with a pool of distance student users was established in 2019. However, a pool of other types of non-normative learners had not yet been established for either round of testing. Another limitation of the study was that we primarily tested on campus servers, so we do not have data on rural or distance learner experiences with the textbook until the second round of testing. In addition, we used only a few devices, a Windows 10 laptop for formal testing and an iPad students briefly viewed afterward. We also did not have an educational technologist as a partner throughout the process.

\section{RESULTS}

Once testing was complete, the scholarly communications librarian and the user experience librarian analyzed the notes and identified areas of common concern and confusion among participants. All participants were familiar with online textbooks from other courses. Participants cited cost as a major consideration when deciding between purchasing print or electronic texts. More than one participant said that electronic textbooks can be cheaper but can be more frustrating to use. Participants had more experience viewing textbooks on laptops. The ability to download texts for reading on a phone was not always available due to publisher restrictions.

\section{Content and Navigation}

Participants liked pictures and visuals to break up the blocks of text. However, one participant expressed a dislike for too many slideshows or other media. Another in the first round of testing liked that there were not "too many" links that brought you out of the textbook, stating it was "annoying to split screen in order to see text plus activity/homework assignment." In the second round of testing, one participant felt the lack of interactive content was best for the first-year students compared to videos and activities in textbooks for advanced courses. That participant also thought the simpler language of the text was more welcoming to first-year students. A 
participant said an iPad would be better than a laptop for viewing this book, because scrolling was easier.

Several users did not find features such as bookmarked sections in the in-browser PDF viewers or Adobe Reader. Participants who did not see or use the table of contents (TOC) continually relied on scrolling through pages to locate content. Only one participant, unprompted, used the Ctrl+F shortcut to keyword search the text. A few other participants viewed the TOC, then entered the desired page number in the top toolbar navigation field. Most of them expected the code of conduct information in one of the tasks to be in the front matter. The emphasis on content reflects Blakiston and Mayden's experience that without a content strategy, it becomes difficult to search and to demonstrate credibility, and it is a challenge to create a coherent, user-centered information architecture. ${ }^{51}$ All participants navigated to the TOC several times to complete tasks, making it a relevant feature. In the second round of testing, one participant preferred the statements and questions at the beginning of the first chapter to learning objectives typically listed in textbooks.

\section{Discovery and Access}

Participants took varied approaches to finding textbooks. One would get links from the professor via email or the syllabus. Others would use the campus bookstore for purchases. One would use the student information system (Raiderlink) to locate information about the textbook. Potential access points to make the RaiderReady textbook discoverable included the institutional repository, the Open Textbook Library, and the local library catalog. The Open Textbook Library was ruled out mostly due to campus-specific adaptations, which were not more substantial for public use than the original College Success. ThinkTech, the institutional repository, was the most viable option and allowed for permanent linking, which worked well with the access points student users mentioned. In the second round of testing, one participant searched for the textbook via the library catalog/discovery system, Google search, and the RaiderReady department website. The course description on the department website listed an open textbook, but the user pointed out that it was not actually linked there.

\section{DISCUSSION}

User testing changed our actions during the project. Interactions with students did not occur during any other stage of the adaptation process before the resource was adopted in the course. Many insights from the testing were indicative of self-reported preferences such as requesting more visuals, preferring print for reading and exercises, and auditory screen reading. We also learned ways that cost impacted how students used textbooks. For example, when we followed up on a participant's comment and asked if they liked to highlight books, the student responded that they try not to mark their books because they want to resell them. Testing also helped us observe actual behaviors among similar users in a way OER toolkits and guidelines alone did not. We learned more about how OER fits into the culture of learning and resources at Texas Tech University and how that may differ from other institutions.

For a visual representation of our workflow, we adapted Billy Meinke's OER production workflow (targeted to creators) because it was an openly available, editable workflow with comprehensive discrete steps. Similar to the CORRE framework adaptations, Meinke's workflow was adapted by others, including the Southern Alberta Institute of Technology (SAIT), Lansing Community College, and the University of Houston, to fit their institutional contexts. ${ }^{52}$ Our process did not include an external peer review process; instead review was done by the editors. Priming and preproduction 
phases in the workflow were relatively quick, occurring in the first two weeks. The bulk of timeabout four weeks - was spent in the development phase. The quality assurance and publishing phases occurred for about two weeks, with most of the time spent on finalizing edits and formatting.

The first round of user testing took about two hours total and redux (revisiting the prototype and implementing changes), along with the format finalization, took about two weeks. Finalization for formatting and redux changes in the first iteration of the text involved Pressbooks troubleshooting. The original timeline for the project was 30 days, but the actual time for the project was 60 days.

The second round of user testing took about two hours total and occurred at the halfway point within a new 60-day deadline for an updated version of the textbook. We acknowledge that even though the actual time spent with users in the first round was limited to two hours, the process also required time for drafting recruitment emails, communicating with volunteers, scheduling testing, and debriefing after sessions. Figure 3 shows our workflow diagram, including a new quality assurance phase (see fig. 4 for detail) based on our case study. It includes prototyping (content and format draft), user testing, and implementing user feedback on the OER prototype.
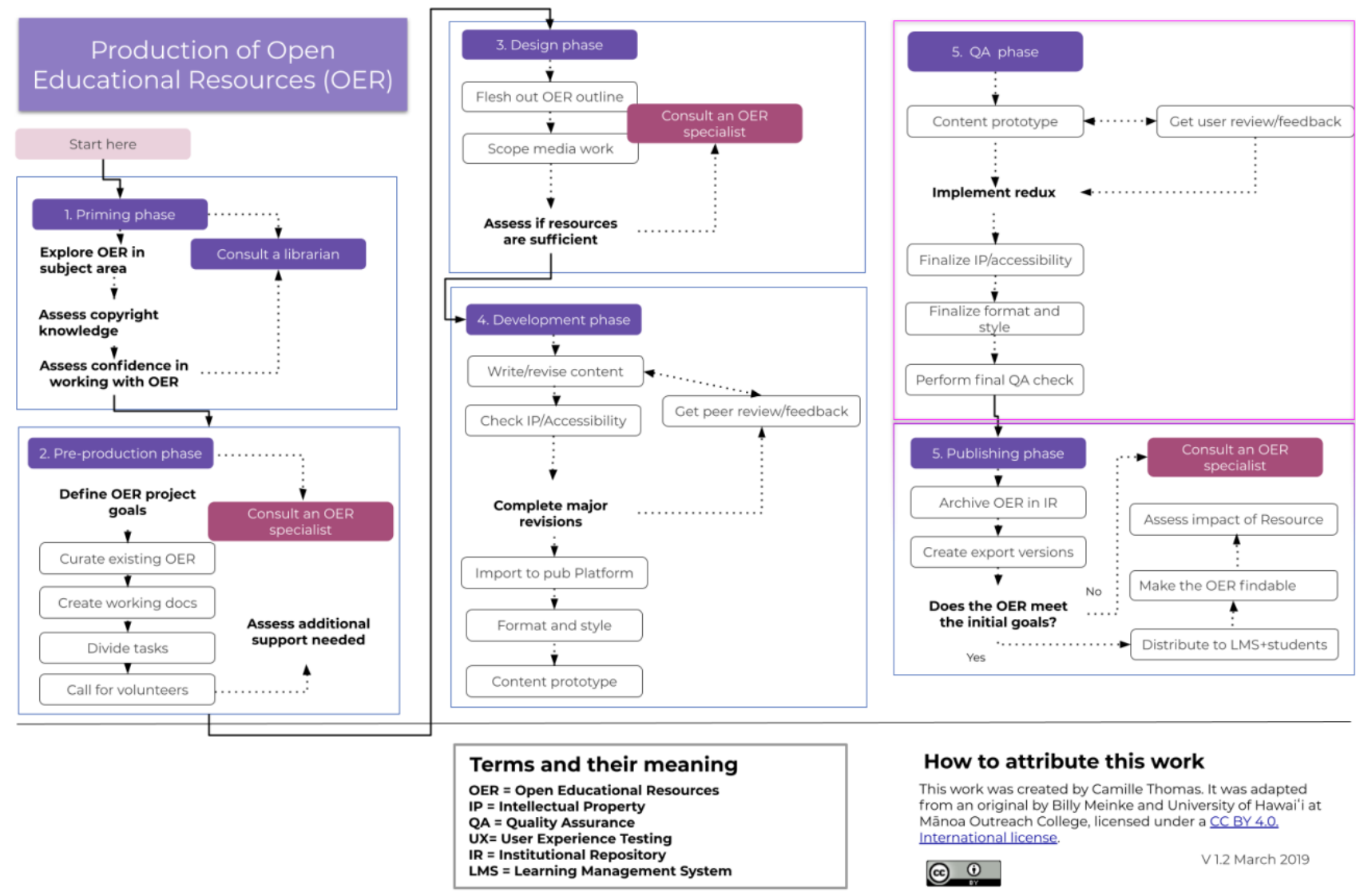

Figure 3. Discrete production workflow including quality assurance phase. This workflow is an adaptation of a workflow by Billy Meinke and University of Hawai'i at Manoa under a CC-BY license. 


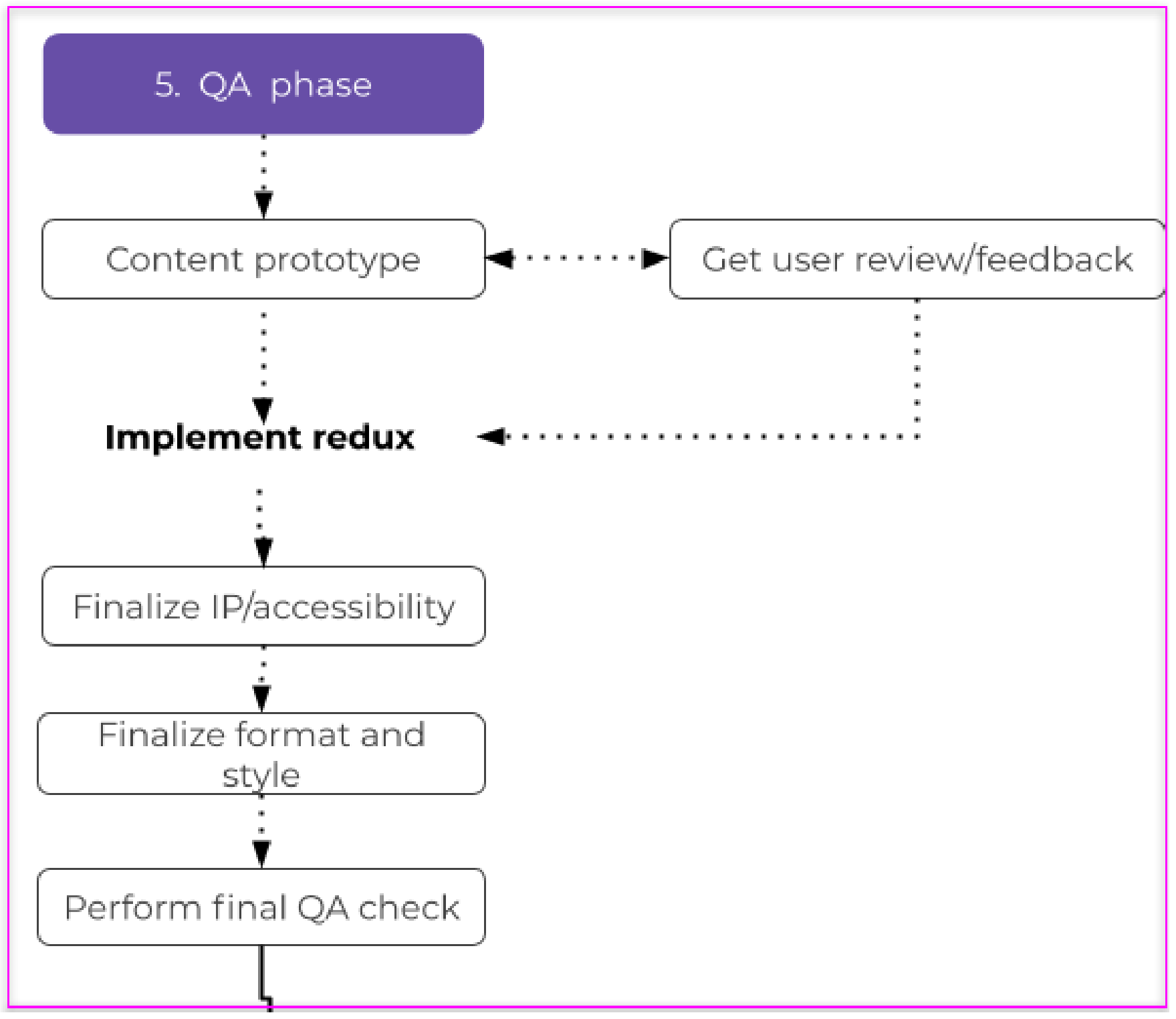

Figure 4. Quality assurance phase with user testing.

We addressed several suggestions participants made during testing to improve the textbook's navigation functionality. We were able to address requests for a linked TOC in the second round of testing. In the first round of testing, formatting was tailored to print PDF format because the editors wanted a print version to be available. We were able to create a linked TOC in the digital PDF format, but not the printable PDF format. We were not aware that the TOC could be changed based on available documentation in the first round of testing, but we were able to successfully troubleshoot this issue in the second round of tests. We were not able to do any customization on the search feature, which was built in. For customization, Pressbooks allows styling through CSS files for three formats (PDF, web page, EPUB) separately. We customized them for look and feel. Many of the requests were constrained by our working knowledge of and the technical limits of Pressbooks, so we added a Tips for PDF Readers and Printing section in the front matter of the textbook during the first round. It is important to note that although these were not major changes to the interface, they gave us insight for iterative changes. Upon reflection, it would have been 
preferable to involve someone with Pressbooks developer experience at the outset. Because we had not led a similar project before, nor worked with the software previously, we were more limited on the changes we could make as a result of testing than we expected. However, after this experience, we know what areas to test and are better prepared to effect actual changes.

We made chapters available separately in the institutional repository to cut down on excessive scrolling, because scrolling through an entire textbook slowed students' ability to study and quickly reference the text. Also, the editors requested digital as well as print access to the textbook through the campus bookstore. The RaiderReady textbook was also added to the library's local records in the catalog. We did not make a web version available through Pressbooks. A web version was not a priority because of the institution-specific customization and because the editors did not request one. Usage statistics from the repository between March 2018 and February 2019 peaked during midterms and at the end of semesters in which the class was taught. Chapters 5, 6, 7, and 8 had the most downloads-the last chapters of the book, likely the chapters students were tested on for the final-with the majority of downloads $(1,368)$ taking place during October 2018. This indicates that the option to download individual chapters appealed to students.

\section{Accessibility}

Testing the textbook with screen readers confirmed the need for an EPUB format of the text. Hyde gives the following guidance for educators using Pressbooks: "PDF accessibility is known to be somewhat limited, and in particular some files are not able to be interpreted by screen readers. The PDF conversion tool that Pressbooks uses does support PDF tagging, which improves screen reader compatibility, but often the best solution is to offer web and e-book versions of a textbook as well as the PDF, so readers can find the format that best suits their needs."53 For PDFs, issues included lack of alt tags, headings not set, and tables and images lacking tags. Adding alt tags was planned early, after they were lost when uploading the WXR (WordPress Extended RSS) file-a WordPress export file in XML format-in Pressbooks, and loss of the alt tags was confirmed during testing at the midpoint of the process. However, due to deadlines and Pressbooks functionality, we were not able to address more of the tagging issues. EPUBs worked much better in tests with screen readers, Apple devices, and e-readers.

Editors preferred that a PDF be used as the primary version and wanted an EPUB for screen readers upon request. Our partners' preference was likely based on the common use of PDFs but it did not comply with the principles of universal or inclusive design. Regarding e-book accessibility, Pressbooks documentation says, "Ebook accessibility is somewhat dictated by the file format standards, which focus on font sizes and screen readers, and improvements are also being made with dynamic content. The International Digital Publishing Forum has a checklist to prompt ebook creators on accessibility functions they can incorporate while creating their content." 54 We made a decision to include multiple formats to take multiple types of use into consideration. In the first round of changes, we included an EPUB alongside the PDF in the repository, so users with disabilities would not have to self-identify by making a request in order to gain access.

Upon learning more about inclusive design after the pilot, we realized we were treating users as a homogeneous group and segregating the more accessible version. In the second round, when we realized the EPUB was not available by separate chapters as was the PDF version, we then made it available by chapter as well. We recommend that evaluating OER according to the International Digital Publishing Forum checklist be incorporated into the QA part of the workflow. 


\section{CONCLUSION}

There is room for future research on iterative testing for OER and testing with more emphasis on mobile devices, testing with deeper investigation into microinteractions concerning accessibility, and testing in workflows that use other publishing platforms. As the creators of the FLOE project suggest, many more customizations can be made to points of user interactions if the software platform for adaptation is open source. Future research may also examine regional and cultural influence on learning and interface preferences.

One change that may support future adaptation projects at Texas Tech University would be modifying internal guidelines that take into consideration previous testing and local context. We also recommend keeping detailed documentation, particularly of steps for changes that are not included in existing guides on OER production.

Creating a memorandum of understanding with partners that clearly outlined responsibilities could have prevented some of the misunderstandings that occurred. For example, when stakeholders discussed producing print copies of the textbook, it wasn't clear what the library's role was. With a short timeline and more work involved than expected, the library was in a position of overpromising and underdelivering. It was apparent that the workflows themselves needed to be open and adaptable to support resources, communities, and processes in local contexts. It was important throughout the process to be aware of our partners' priorities (e.g., instructional preferences, cost to students, departmental buy-in), because we had to balance these priorities with user feedback.

We recommend having specific roles for content strategists, educational technologists, and developers in workflows during OER production. The work of creating workflows, assigning roles, and creating standards for OER content currently falls on librarians, instructional designers, and creators. As librarians seek the most sustainable workflows, it will be beneficial to emphasize investing in the quality assurance stages of OER production and evenly distributing responsibilities. This can be done through collaborative partnerships or by hiring additional positions. If other institutions were to scale the practices from our case study, ideally, librarians would take responsibility for adding roles or formalized work to the scope of either UX or OER departments so that it becomes normalized in OER workflows. We recommend working with editors to advocate for one textbook format that addresses a variety of learning needs. We plan to use these experiences, along with existing resources, to include inclusive and user-friendly recommendations in policies and guidelines for OER adaptation.

Conducting user testing did challenge assumptions about student use of OER by librarians and editing instructors. While we referred to toolkits, guidelines, and best practices, internal testing allowed us to make improvements to several specific microinteractions students encountered while using the text. It was very feasible to incorporate testing into the workflow. We were able to directly observe user information behavior from members of the community that the resource was intended to serve. 


\section{APPENDIX: USABILITY TEST METHOD}

\section{Pretest questions}

1. What is your academic classification? (undergraduate, graduate, faculty)

2. Have you ever used an e-textbook or a digital textbook in one of your classes? (If yes, ask for course details.)

Tasks to observe

1. Imagine you needed to get a copy of the digital textbook Raider Ready: Unmasking the Possibilities of College Success. How would you go about finding it? It will help us if you think out loud as you go along-tell us what you're looking at, what you're trying to do, what you're thinking.

2. [If the tester is unable to locate the digital textbook, the moderator will open it.] Please take a couple of minutes to look at this textbook. Explore and click on a link or two.

3. For the next task, imagine an instructor asked you to locate the chapter activities for chapter 1 . Could you show us how you would locate those?

4. For the final task, could you find the student code of conduct?

\section{Posttest questions}

1. What were your impressions of this resource?

2. What did you like? Dislike? What would you change?

3. How easy or difficult was it to find what you wanted? Please explain.

4. Is there anything else about your experience using this textbook today that you'd like to tell us? 


\section{ENDNOTES}

${ }^{1}$ Sonya Betz and Robyn Hall, "Self-archiving with Ease in an Institutional Repository: Microinteractions and the User Experience," Information Technology and Libraries 34, no. 3 (September 21, 2015): 44-45, https://doi.org/10.6017/ital.v34i3.5900.

${ }^{2}$ Anita R. Walz, “Open and Editable: Exploring Library Engagement in Open Educational Resource Adoption, Adaptation and Authoring," Virginia Libraries 61 (January 2015): 23, http://hdl.handle.net/10919/52377.

${ }^{3}$ Stephen Whitfield and Zoe Robinson, “Open Educational Resources: The Challenges of 'Usability' and Copyright Clearance," Planet 25, no. 1 (2012): 52, https://doi.org/10.11120/plan.2012.00250051.

${ }^{4}$ Walz, "Open and Editable," 24.

${ }^{5}$ Andy Lane, "From Pillar to Post: Exploring the Issues Involved in Repurposing Distance Learning Materials for Use as Open Educational Resources" (working paper, UK Open University, December 2006), accessed August 1, 2018, http://kn.open.ac.uk/public/document.cfm?docid=9724.

${ }^{6}$ Andy Arana et al. eds., "Open Logic Project," University of Calgary Faculty of Arts and the Campus Alberta OER Initiative, accessed April 26, 2019, http://openlogicproject.org/; Robin DeRosa, The Open Anthology of Earlier American Literature (Public Commons Publishing, 2015), https://openamlit.pressbooks.com/; Timothy Robbins, "Case Study: Expanding the Open Anthology of Earlier American Literature," in A Guide to Making Open Textbooks with Students, ed. Elizabeth Mays (The Rebus Community for Open Textbook Creation, 2017), https://press.rebus.community/makingopentextbookswithstudents/chapter/case-studyexpanding-open-anthology-of-earlier-american-literature/.

7 Walz, “Open and Editable," 24.

8 Billy Meinke, “Discovering OER Production Workflows," UH OER (blog), University of Hawai'i, December 23, 2016, https://oer.hawaii.edu/discovering-oer-production-workflows/.

${ }^{9}$ Betz and Hall, "Self-archiving with Ease," 44.

${ }^{10}$ Beth St. Jean et al., "Unheard Voices: Institutional Repository End-Users," College \& Research Libraries 72, no. 1 (January 2011): 23, https://doi.org/10.5860/crl-71r1.

11 Jutta Treviranus et al., "An Introduction to the FLOE project," in International Conference on Universal Access in Human-Computer Interaction, Universal Access to Information and Knowledge, ed. Constantine Stephanidis and Margherita Antona, UAHCI 2014 (June 2014), Lecture Notes in Computer Science 8514: 454, https://doi.org/10.1007/978-3-319-07440$\underline{542 .}$.

${ }^{12}$ Sarah Crissinger, "A Critical Take on OER Practices: Interrogating Commercialization, Colonialism, and Content," In the Library with the Lead Pipe, October 21, 2015, http://www.inthelibrarywiththeleadpipe.org/2015/a-critical-take-on-oer-practicesinterrogating-commercialization-colonialism-and-content/; Diane Harley, "Why 
Understanding the Use and Users of Open Education Matters," in Opening Up Education: The Collective Advancement of Education through Open Technology, Open Content, and Open Knowledge, ed. Toru Iiyoshi and M.S. Vijay Kumar (Cambridge, MA: The MIT Press, 2008), 197212.

${ }^{13}$ Harley, "Why Understanding," 208.

14 Tom Carey and Gerard L. Hanley, "Extending the Impact of Open Educational Resources through Alignment with Pedagogical Content Knowledge and Institutional Strategy: Lessons Learned from the MERLOT Community Experience," in Opening Up Education: The Collective Advancement of Education through Open Technology, Open Content, and Open Knowledge, ed. Toru Iiyoshi and M.S. Vijay Kumar (Cambridge, MA: The MIT Press, 2008), 238.

${ }^{15}$ Rebecca Blakiston and Shoshana Mayden, "How We Hired a Content Strategist (And Why You Should Too)," Journal of Web Librarianship 9, no. 4 (2015): 202-6, https://doi.org/10.1080/19322909.2015.1105730; “Our Team,” OpenStax, Rice University, accessed December 9, 2019, https://openstax.org/team.

${ }^{16}$ Maria Nuccilli, Elliot Polak, and Alex Binno, "Start with an Hour a Week: Enhancing Usability at Wayne State University Libraries," Weave: Journal of Library User Experience 1, no. 8 (2018), https://doi.org/10.3998/weave.12535642.0001.803.

${ }^{17}$ Jakob Nielsen and Thomas K. Landauer, "A Mathematical Model of the Finding of Usability Problems," in Proceedings of the INTERACT'93 and CHI'93 Conference on Human Factors in Computing Systems (May 1993): 211-12, https://doi.org/10.1145/169059.169166.

${ }^{18}$ Simone Borsci et al., "Reviewing and Extending the Five-User Assumption: A Grounded Procedure for Interaction Evaluation," in ACM Transactions on Computer-Human Interaction 20, no. 5, article 29 (November 2013), 18-19, http://delivery.acm.org/10.1145/2510000/2506210/a29-borsci.pdf.

19 Treviranus et al., "FLOE project," 454.

${ }^{20}$ Laura Icela González-Pérez, María-Soledad Ramírez-Montoya, and Francisco J. García-Peñalvo, "User Experience in Institutional Repositories: A Systematic Literature Review," International Journal of Human Capital and Information Technology Professionals 9, no. 1 (January-March 2018): 79, 84, https://doi.org/10.4018/IJHCITP.2018010105; Betz and Hall, "Self-archiving with Ease," 45; St. Jean et al., "Unheard Voices," 23, 36-37, 40.

${ }^{21}$ Meinke, "Discovering OER Production Workflows"; Nuccilli, Polak, and Binno, "Start with an Hour."

${ }^{22}$ Steven D. Eppinger, Murthy V. Nukala, and Daniel E. Whitney, "Generalised Models of Design Iteration Using Signal Flow Graphs," Research in Engineering Design 9, no. 2 (1997): 112; Helen Timperley et al., Teacher Professional Learning and Development (Wellington, New Zealand: Ministry of Education, 2007), http://www.oecd.org/education/school/48727127.pdf.

${ }^{23}$ Eppinger, Nukala, and Whitney, “Design Iteration,” 112-13. 
${ }^{24}$ Walz, "Open and Editable," 23; Blakiston and Mayden, "How We Hired a Content Strategist," 203.

${ }^{25}$ Walz, "Open and Editable," 28.

${ }^{26}$ Harley, "Why Understanding," 201-6.

${ }^{27}$ Scott Woodward, Adam Lloyd, and Royce Kimmons, "Student Voice in Textbook Evaluation: Comparing Open and Restricted Textbooks," International Review of Research in Open and Distributed Learning 18, no. 6 (September 2017), 150-63, https://doi.org/10.19173/irrodl.v18i6.3170.

${ }^{28}$ Meinke, "Discovering OER Production Workflows."

${ }^{29}$ Samuel K. Nikoi et al., "CORRE: A Framework for Evaluating and Transforming Teaching Materials into Open Educational Resources," Open Learning: The Journal of Open, Distance and e-Learning 26, no. 3 (2011), 194-99, https://doi.org/10.1080/02680513.2011.611681.

30 “CORRE 2.0," Institute of Learning Innovation, University of Leicester, accessed April 25, 2019, https://www2.le.ac.uk/departments/beyond-distance-researchalliance/projects/ostrich/corre-2.0.

${ }^{31}$ Betz and Hall, "Self-archiving with Ease," 45-46.

${ }^{32}$ André Constantino da Silva et al., "Portability and Usability of Open Educational Resources on Mobile Devices: A Study in the Context of Brazilian Educational Portals and Android-Based Devices" (paper, International Conference on Mobile Learning 2014, Madrid, Spain, February 28-March 2, 2014), 198, https://eric.ed.gov/?id=ED557248.

${ }^{33}$ Sarah Morehouse, "OER Bootcamp 3-3: OERs and Usability," YouTube video, 3:16, March 2, 2018, https://www.youtube.com/watch?v=CnCXbcS-2gM.

${ }^{34}$ Krista Godfrey, "Creating a Culture of Usability," Weave: Journal of Library User Experience 1, no. 3 (2015), https://doi.org/10.3998/weave.12535642.0001.301; Peter Morville, "User Experience Design," Semantic Studios, June 21, 2004, http://semanticstudios.com/user experience design/.

${ }^{35}$ Meinke, "Discovering OER Production Workflows."

${ }^{36}$ Cynthia Ng, "A Practical Guide to Improving Web Accessibility," Weave: Journal of Library User Experience 1, no. 7 (2017), https://doi.org/10.3998/weave.12535642.0001.701; Whitney Quesenbery, "Usable Accessibility: Making Web Sites Work Well for People with Disabilities," UX Matters, February 23, 2009, http://www.uxmatters.com/mt/archives/2009/02/usableaccessibility-making-web-sites-work-well-for-people-with-disabilities.php.

${ }^{37} \mathrm{Ng}$, "Improving Web Accessibility."

${ }^{38}$ Amanda Coolidge et al., Accessibility Toolkit - 2nd Edition (Victoria, B.C.: BCcampus, 2018), 1-71, https://opentextbc.ca/accessibilitytoolkit/. 
${ }^{39}$ Vassilis Kourbetis and Konstantinos Boukouras, "Accessible Open Educational Resources for Students with Disabilities in Greece," in Universal Access in Human-Computer Interaction, Universal Access to Information and Knowledge, ed. Constantine Stephanidis and Margherita Antona, UAHCI 2014 (June 2014), Lecture Notes in Computer Science 8514: 349-57, https://doi.org/10.1007/978-3-319-07440-5 32.

${ }^{40}$ Treviranus et al., "FLOE project,” 455-56.

${ }^{41}$ Treviranus et al., 456-57.

${ }^{42}$ Treviranus et al., 456-57.

${ }^{43} \mathrm{Ng}$, "Improving Web Accessibility"; Treviranus et al., "FLOE project," 460-61.

${ }^{44}$ Treviranus et al., "FLOE project," 461.

452018 Academic Student Ebook Experience Survey Report (Library Journal Research, 2018): 6, accessed May 3, 2019, https://mediasource.formstack.com/forms/2018_academic_student_ebook experience_survey report.

${ }^{46}$ Michael Gorrell, "The eBook User Experience in an Integrated Research Platform," Against the Grain 23, no. 5 (December 2014): 38; Robert Slater, "Why Aren't E-Books Gaining More Ground in Academic Libraries? E-Book Use and Perceptions: A Review of Published Literature and Research," Journal of Web Librarianship 4, no. 4 (2010): 305-31; Joelle Thomas and Galadriel Chilton, "Library E-Book Platforms Are Broken: Let's Fix Them," Academic E-Books: Publishers, Librarians, and Users (2016): 249-62; Christina Mune and Ann Agee, "Ebook Showdown: Evaluating Academic Ebook Platforms from a User Perspective," in Creating Sustainable Community: The Proceedings of the ACRL 2015 Conference (2015): 25-28; Laura Muir and Graeme Hawes, “The Case for E-Book Literacy: Undergraduate Students' Experience with EBooks for Course Work," The Journal of Academic Librarianship 39, no. 3 (2013): 260-74; Esta Tovstiadi, Natalia Tingle, and Gabrielle Wiersma, "Academic E-book Usability from the Student's Perspective," Evidence Based Library and Information Practice 13, no. 4 (2018): 7087.

${ }^{47}$ Erin Dorris Cassidy, Michelle Martinez, and Lisa Shen, "Not in Love, or Not in the Know? Graduate Student and Faculty Use (and Non-Use) of E-books," The Journal of Academic Librarianship 38, no. 6 (2012): 326-32; Gorrell, "The eBook User Experience," 36-40.

${ }^{48}$ Jo R. Jardina and Barbara S. Chaparro, "Investigating the Usability of E-Textbooks Using the Technique for Human Error Assessment," Journal of Usability Studies 10, no. 4 (2015): 140-59.

${ }^{49}$ Steve Krug, Rocket Surgery Made Easy (Berkeley, CA: New Riders, 2010), 146-53.

${ }^{50}$ Danielle A. Becker and Lauren Yannotta, "Modeling a Library Website Redesign Process: Developing a User-Centered Website Through Usability Testing," Information Technology and Libraries 32, no. 1 (March 2013): 9-10.

${ }^{51}$ Blakiston and Mayden, "How We Hired a Content Strategist," 194. 
52 Jessica Norman, SAIT OER Workflow, May 2019, accessed July 14, 2020, https://docs.google.com/drawings/d/1XVIpU9S4Bb32K3GblNVw4uy1Ely9rTXnr8bkFDM5yk/; Regina Gong, OER Production Workflow, accessed July 14, 2020, http://libguides.lcc.edu/oer/adopt; Ariana E. Santiago, OER Adoption Workflow - Visual Overview, April 2019, accessed July 14, 2020, https://docs.google.com/drawings/d/1cZQHpGpQyrr46Vm5IytOEMYQj-s1zr0P-M-LJ16Rtto/; Meinke, "Discovering OER Production Workflows."

53 Zoe Wake Hyde, “Accessibility and Universal Design," in Pressbooks for EDU Guide (Pressbooks.com, 2016), https://www.publiconsulting.com/wordpress/eduguide/.

${ }^{54}$ Hyde. 